\title{
Generation of Controlled Low Pressures of Nitrogen by Means of Dissociation Equilibria
}

\author{
Ronald H. Orcutt \\ Institute for Basic Standards, National Bureau of Standards, \\ Washington, D.C. 20234
}

(October 3, 1969)

\begin{abstract}
It is shown that fixed low pressures of nitrogen in the vacuum region can be generated by chemical dissociation in a system at equilibrium at constant temperature. Dissociation pressures ranging from $2 \times 10^{-5}$ to 0.7 torr $\left(3 \times 10^{-3}\right.$ to $\left.90 \mathrm{~N} \cdot \mathrm{m}^{-2}\right)$, corresponding to temperatures of 740 to $1150 \mathrm{~K}$, for the reaction

$$
\mathrm{Ba}_{3} \mathrm{~N}_{2} \rightleftarrows \frac{3}{2} \mathrm{Ba}_{2} \mathrm{~N}+\frac{1}{4} \mathrm{~N}_{2}
$$
\end{abstract}

have been measured. The pressures, $p$, in $\mathrm{N} \cdot \mathrm{m}^{-2}$ are represented by the equation

$$
\ln p=(22.02 \pm 0.14)-\frac{(20,080 \pm 140)}{T},
$$

where $T$ is the absolute temperature, and the uncertainties are least squares estimates of the standard deviations of the parameters.

Key words: Barium nitride; dissociation equilibria; nitrides; nitrogen; thermodynamic properties; vacuum; vacuum measurement.

\section{Introduction}

The calibration of a vacuum-measuring device at pressures less than $10^{-3}$ torr is difficult, owing to the lack of both absolute and relative standards. Furthermore, most devices normally used for pressure measurement at this level are sensitive to composition as well as to pressure. Thus, any useful standard should control both of these variables simultaneously. The present paper reports studies concerned with the development of a procedure for establishing "fixed pressure points" in the high-vacuum region which provide such control.

The procedure relies on the fact that, for a twocomponent system consisting of two solid phases in equilibrium with a gas phase, the pressure of the gas is a function only of temperature. Owing to its widespread use as a reference medium, nitrogen was chosen for the gas phase [1]. ${ }^{1}$ The systems, consisting of nitrogen, metal, and/or metallic nitride(s), of the following metals were investigated: magnesium, manganese, boron, chromium, and barium. For temperatures less than $1300 \mathrm{~K}$ and pressures below one torr, only the barium/nitrogen system attained an equilib-

\footnotetext{
${ }^{1}$ Figures in brackets indicate the literature references at the end of this paper.
}

rium state rapidly enough for consideration as a possibly useful standard.

\section{Concept}

Ariya et al. [2] have shown that barium nitride decomposes according to the reaction

$$
\mathrm{Ba}_{3} \mathrm{~N}_{2}(\mathrm{~s}) \rightleftarrows \frac{3}{2} \mathrm{Ba}_{2} \mathrm{~N}(\mathrm{~s})+\frac{1}{4} \mathrm{~N}_{2}(\mathrm{~g}) \text {. }
$$

The application of the second law of thermodynamics to this system at equilibrium gives the approximate expression

$$
\ln p_{\mathrm{N}_{2}}=4\left(\frac{\Delta S^{\circ}}{R}-\frac{\Delta H^{\circ}}{R T}\right),
$$

relating the pressure of nitrogen, $p_{\mathrm{N}_{2}}$, to the absolute temperature $T$, in terms of the entropy and enthalpy changes, $\Delta S^{\circ}$ and $\Delta H^{\circ}$, for the reaction. Assuming that $\Delta S^{\circ}$ and $\Delta H^{\circ}$ are nearly independent of temperature and are determined by measurements of $p$ and $T$ over a range of values in which $p$ can be determined absolutely and accurately, values of $p$ can be calculated for lower temperatures by use of eq (2), thus extrapolating the pressure into a region where it 
cannot be absolutely determined, providing that the system reaches equilibrium.

Two series of measurements, one at relatively high pressures $(0.05 \text { to } 0.7 \text { torr })^{2}$ and the other at low pressures $\left(2 \times 10^{-5}\right.$ to 0.05 torr $)$, are reported here. The consistency of these measurements supports the validity of such an extrapolation.

\section{Apparatus}

The vacuum system used for these measurements is shown schematically in figure 1 [3]. The fluid manometer was of the type described by Thomas and Cross [4], and used a silicone material of low vapor pressure as a working fluid. A commercial high-pressure ion gage [5] tube was used for the low-pressure measurements.

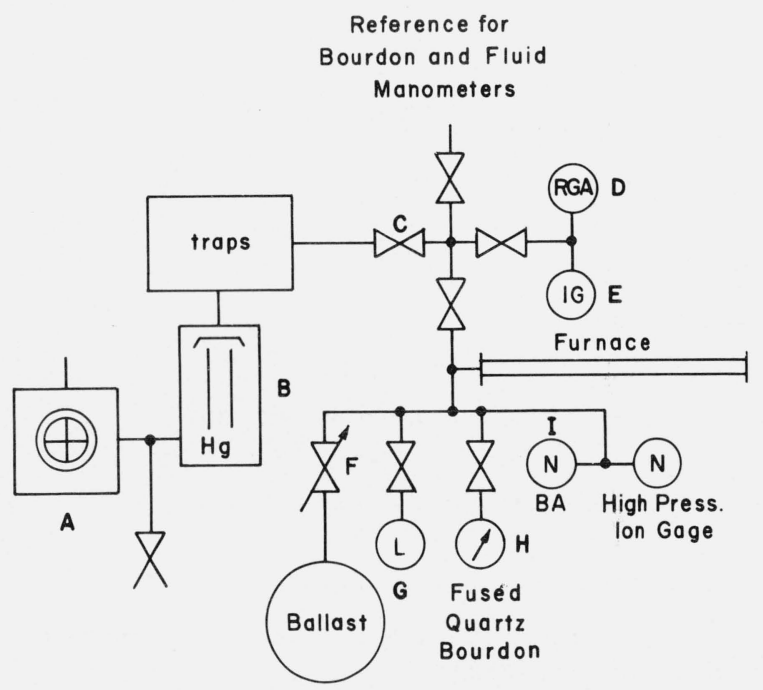

FIGURE 1. Furnace/vacuum system (schematıc).

A: mechanical pump; B: mercury diffusion pump; C: valve; D: residual gas analyzer (omegatron); $\mathrm{E}$ : ionization gage; $\mathrm{F}$ : leak valve; $\mathrm{G}$ : fluid manometer; $\mathrm{H}$ : fused quartz bourdon gage; I: nude ionization gage (Bayard-Alpert type).

The system above the traps was constructed from stainless steel. All connections, save that to the furnace, were either by tungsten-inert gas penetration weld or by bolted aluminum foil or copper gasket.

The 99 percent alumina ceramic furnace tube was provided with tapered ends, which were waxed into matching stainless steel flanges with a low-vaporpressure wax. During operation of the furnace, the waxed joints were kept cool by means of water jackets.

The furnace was a conventional clamshell-type combustion tube furnace. Temperature control above $900{ }^{\circ} \mathrm{C}$ was obtained from a proportional controller using a $\mathrm{Pt} / \mathrm{Pt}-\mathrm{Rh}$ thermocouple as sensing element; below this temperature a similar controller employing a platinum resistance thermometer as sensor was used.

Temperature on the IPTS scale of 1948 [14] was measured with a calibrated $\mathrm{Pt} / \mathrm{Pt}-10$ percent $\mathrm{Rh}$ thermocouple whose emf was determined potentiometrically with an accuracy of better than $1 \mu \mathrm{V}$.

${ }^{2} 1$ torr $=1.33322 \times 10^{2} \mathrm{~N} \cdot \mathrm{m}^{-2}$
Separate measurements showed that the sample temperature did not differ from that indicated by more than $0.5^{\circ} \mathrm{C}$.

The pressure measurements reported in table 1 from 0.05 to 1 torr were made with the fused-quartz bourdon gage, whereas pressures below 0.05 torr were measured with the high-pressure ion gage, and are marked with the symbol \#. The precision and calibration uncertainty of the bourdon gage was about $5 \times 10^{-4}$ torr; the gage was periodically calibrated against the standard manometer [4] and showed no drift over the period of the measurements. The reference pressure for both the manometer and the bourdon gage was less than $5 \times 10^{-8}$ torr. The high-pressure ion gage was operated with its emission current regulated to better than 0.1 percent by means of an emission regulator developed at the Bureau [6]. The ion currents were measured with a precision of at least 1 percent by means of a calibrated electrometer. The high-pressure ion gage was also periodically calibrated against the standard manometer and was free from drift over the time of the measurements. Its precision of calibration was 1 to 2 percent, the limitation being set by the current measurement. It is conservatively estimated that, for pressures greater than 0.05 torr, combined errors

TABLE 1. Dissociation pressures for the reaction $\mathrm{Ba}_{3} \mathrm{~N}_{2} \rightleftarrows \frac{3}{2} \mathrm{Ba}_{2} \mathrm{~N}+\frac{1}{4} \mathrm{~N}_{2}$ as a function of temperature

\begin{tabular}{|c|c|c|}
\hline$T_{48}(\mathrm{~K})$ & $p_{\text {measured }}$ (torr) & $p_{\text {corrected }}$ (torr) \\
\hline 738 & $2.11(-5) * \#$ & $3.18(-5)$ \\
\hline 748 & $4.80(-5) \#$ & $7.28(-5)$ \\
\hline 764 & $5.95(-5) \#$ & $9.11(-5)$ \\
\hline 770 & $9.20(-5) \#$ & $1.42(-4)$ \\
\hline 792 & $2.06(-4) \#$ & $3.20(-4)$ \\
\hline 795 & $1.64(-4) \#$ & $2.55(-4)$ \\
\hline 815 & $3.78(-4) \#$ & $5.93(-4)$ \\
\hline 844 & $7.87(-4) \#$ & $1.24(-3)$ \\
\hline 845 & $8.30(-4) \#$ & $1.31(-3)$ \\
\hline 874 & $1.90(-3) \#$ & $2.95(-3)$ \\
\hline 894 & $4.26(-3) \#$ & $6.30(-3)$ \\
\hline 927 & $8.00(-3) \#$ & $1.11(-2)$ \\
\hline 934 & $1.10(-2) \#$ & $1.47(-2)$ \\
\hline 958 & $1.68(-2) \#$ & $2.12(-2)$ \\
\hline 989 & $3.34(-2) \#$ & $3.84(-2)$ \\
\hline 1000 & $4.9(-2)$ & $5.4(-2)$ \\
\hline 1023 & $6.8(-2)$ & $7.3(-2)$ \\
\hline 1025 & $7.10(-2) \#$ & $7.56(-2)$ \\
\hline 1029 & $8.9(-2)$ & $9.3(-2)$ \\
\hline 1030 & $1.04(-1)$ & $1.08(-1)$ \\
\hline 1042 & $9.5(-2)$ & $9.9(-2)$ \\
\hline 1048 & $1.23(-1)$ & $1.27(-1)$ \\
\hline 1067 & $1.78(-1)$ & $1.82(-1)$ \\
\hline 1082 & $2.36(-1)$ & $2.36(-1)$ \\
\hline 1084 & $2.90(-1)$ & $2.90(-1)$ \\
\hline 1112 & $3.98(-1)$ & $3.98(-1)$ \\
\hline 1132 & $5.55(-1)$ & $5.55(-1)$ \\
\hline 1133 & $5.23(-1)$ & $5.23(-1)$ \\
\hline 1134 & $5.57(-1)$ & $5.57(-1)$ \\
\hline 1135 & $5.81(-1)$ & $5.81(-1)$ \\
\hline 1135 & $6.22(-1)$ & $6.22(-1)$ \\
\hline 1150 & $7.24(-1)$ & $7.24(-1)$ \\
\hline
\end{tabular}

*The notation $a(n)$ means $a \cdot 10^{n}$; thus, for example, $2.11(-5)$ means $2.11 \times 10^{-5}$. \#Measurements were made with ion gage. 
of temperature and pressure measurement do not exceed 5 percent of the pressure on an absolute basis. At lower pressures the absolute error is thought to be less than 20 percent, the larger value being due to the uncertainty of extrapolation.

Samples of $\mathrm{Ba}_{3} \mathrm{~N}_{2}$ in alumina ceramic trays were enclosed in a nickel shield whose function was to insure that there should be a negligible temperature gradient across the sample. The container and its relation to the furnace tube are shown in figure 2 .

\section{Experimental Procedures}

Commercial samples of $\mathrm{Ba}_{3} \mathrm{~N}_{2}$ in powder form were used for the measurements. Two samples from different lots gave identical results; in addition, a sample prepared in situ from $\mathrm{Ba}$ and $\mathrm{N}_{2}$ gave the same results. Since the material decomposes in the presence of water, samples were handled under an atmosphere of dry nitrogen.

Samples were transferred to the furnace in the nickel sample shield and the furnace evacuated. The samples were found to contain large quantities of absorbed nitrogen, the bulk of which was removed by pumping on the samples for several hours at 700 to $750{ }^{\circ} \mathrm{C}$ under a nitrogen pressure of about 0.1 torr. The temperature for which the dissociation pressure was to be measured was selected and the furnace allowed to stabilize. The pressure in the system was then reduced to a value below the anticipated decomposition pressure for the set temperature, and the sample was isolated from the pump. The increase of pressure was then observed as a function of time: If the sample had been completely degassed, the pressure reached a constant value after a period of from one to three hours; otherwise the pressure would continue to rise, nearly linearly with time.

In the event that a constant pressure was not attained, the sample was further degassed and the procedure repeated until a constant value was obtained. The rate of approach to a stable value was found to be a linear function of the logarithm of time, and was apparently nearly independent of temperature.

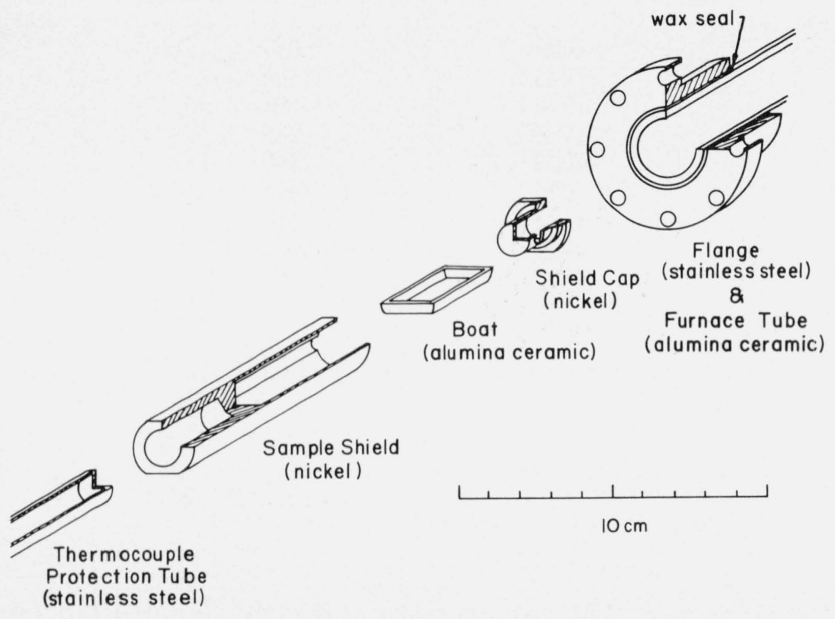

FigURE 2. Sample holder detail (oblique drawing).

\section{Results}

Measurements of the dissociation pressure of $\mathrm{Ba}_{3} \mathrm{~N}_{2}$ made at 32 temperatures ranging from 740 to $1150 \mathrm{~K}$ with corresponding pressures of from $2 \times 10^{-5}$ to 0.7 torr are given in table 1 . The data were fitted by ordinary least squares [7] to the equation

$$
(\ln p)=A+B\left(\frac{1}{T}\right) .
$$

The values of $A$ and $B$ resulting from the fit were $18.17 \pm 0.14$ and $-21,250 \pm 130$, respectively, for $p$ in torr. The uncertainties given are the estimates of the standard deviations of the parameters: The estimate of the standard deviation of the fit was 0.12 in the logarithm of pressure. The data and the least squares line are plotted in figure 3.

In addition to the results on dissociation, some results for recombination at pressures from 0.05 to 0.7 torr were obtained. These results, which are given in the appendix, were on the average 15 percent higher than the results obtained by decomposition; it was at first thought that the system exhibited hysteresis as has been observed in some other systems [8]. It seems more likely, however, that equilibrium was not attained because of a very slow rate [9].

Since the gages used for determining the dissociation pressures were operated at temperatures different from that of the sample, the results must be corrected for thermomolecular pressure gradients (thermal transpiration). The data span the transition region from viscous to molecular flow; thus, the correction factor can range from unity for viscous flow to $\left(T_{2} / T_{1}\right)^{1 / 2}$ for molecular flow, where $T_{2}$ is the furnace temperature and $T_{1}$ that of the gage.

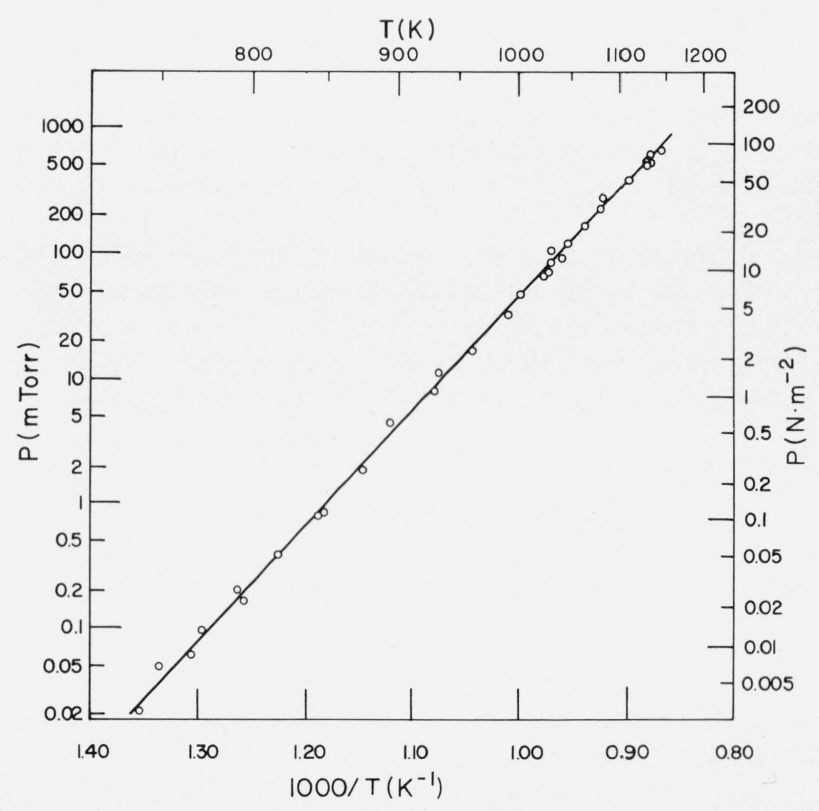

FIGURE 3. Dissociation pressure of $\mathrm{Ba}_{3} \mathrm{~N}_{2}$ as a function of temperature. 
There exists no exact theory for calculating the correction factor in the transition region. In order to estimate the correction the empirical equation of Liang [10] was used, although its accuracy is not known. This equation for the correction factor $R$ can be written in the form

$$
R=\frac{p_{1}}{p_{2}}=\frac{\alpha\left(\varphi_{g} x\right)^{2}+\beta\left(\varphi_{g} x\right)+\left(T_{1} / T_{2}\right)^{1 / 2}}{\alpha\left(\varphi_{g} x\right)^{2}+\beta\left(\varphi_{g} x\right)+1},
$$

where $x=p_{2} d$, with $p_{2}$ in torr and $d$, in millimeters, the diameter of the tubing joining the regions at temperatures $T_{1}$ and $T_{2}$ with $T_{1} \leqslant T_{2}$.

Using values of the parameters, $\alpha=2.13$ and $\beta=4.82\left[1-\left(T_{1} / T_{2}\right)^{1 / 2}\right] \quad[10]$ and $\varphi_{g}=3.53 \quad[11]$ taken from the literature, together with $d=5 \mathrm{~mm}$ and $T_{1}=325 \mathrm{~K}$, values of $p_{2}$ corresponding to the measured values of $p_{1}$ were calculated; these values along with the measured values of $p_{1}$ and the temperatures are given in table 1 . The resulting values of $p_{2}$ yielded a linear relationship within experimental error between the logarithm of pressure and the reciprocal temperature. Fitting the corrected dissociation pressures to eq (3) yielded the results: $A=17.13 \pm 0.14, B=-20,080$ \pm 140 , and $s=0.12$, where the uncertainties are the estimates of the standard deviations of the parameters, $s$ is the estimate of the standard deviation of the fit, and the pressures are given in torr.

These values correspond to values of $21.8 \mathrm{~J} \cdot \mathrm{K}^{-1}$ $\cdot \mathrm{mol}^{-1}$ and $41.7 \mathrm{~kJ} \cdot \mathrm{mol}^{-1}$, respectively, for $\Delta S^{\circ}$ and $\Delta H^{\circ}$ for the reaction represented by eq (1). Ariya et al. [2] report a value of $8.8 \mathrm{kcal} \cdot \mathrm{mol}^{-1}\left(36.8 \mathrm{~kJ} \cdot \mathrm{mol}^{-1}\right)$ for the enthalpy change of this reaction at $298 \mathrm{~K}$. Since the heat capacities of $\mathrm{Ba}_{3} \mathrm{~N}_{2}$ and $\mathrm{Ba}_{2} \mathrm{~N}$ have not been determined as a function of temperature, the present value (which corresponds to $\Delta H^{\circ}$ at about $950 \mathrm{~K})$ cannot be corrected so as to make a valid comparison with the value at $298 \mathrm{~K}$.

It should be pointed out that reasonable estimates of $\Delta S^{\circ}$ for reaction (1) are significantly greater than the value obtained from the experimental results $[12,13]$. This suggests the possibility that the system was not at equilibrium, or that reaction (1) is not correct.

In order to assess the accuracy of these values of $A$ and $B$, it is necessary to measure the thermomolecular pressure gradients for the specific vacuum system over the temperature and pressure region of interest. This is a subject for further investigation.

\section{Summary Remarks}

Dissociation pressures in torr for the reaction

$$
\mathrm{Ba}_{3} \mathrm{~N}_{2}(s) \rightleftarrows \frac{3}{2} \mathrm{Ba}_{2} \mathrm{~N}(s)+\frac{1}{4} \mathrm{~N}_{2}(g)
$$

are represented over a range of temperatures from 740 to $1150 \mathrm{~K}$ by the equation

$$
\ln p=(17.13 \pm 0.14)-\frac{(20,080 \pm 140)}{T}
$$

and the pressures in $\mathrm{N} \cdot \mathrm{m}^{-2}$ are represented by the equation

$$
\ln p=(22.02 \pm 0.14)-\frac{(20,080 \pm 140)}{T}
$$

where the uncertainties are least squares estimates of the standard deviations of the parameters.

The reaction goes to equilibrium in times of a few hours and the rate of approach to equilibrium is independent of temperature. This reaction can be used to generate stable and reproducible pressures of nitrogen in the range $10^{-5}$ to 1 torr, and is thus useful in checking the variation in response of pressure measuring devices.

In order to use this means of checking, it is necessary only to append a chamber with suitable valving containing a sample of $\mathrm{Ba}_{3} \mathrm{~N}_{2}$ to one's vacuum system. Means of controlling and measuring the sample temperature must also be provided.

Once the corrections for thermomolecular pressure gradients are known and the true values of $\Delta H^{\circ}$ and $\Delta S^{\circ}$ are derived, the technique becomes absolute.

The possible role of hysteresis in this system and the feasibility of extending the measurements to lower pressures are subjects for further investigation.

The author is grateful to Stanley Ruthberg for many helpful discussions concerning this work and to William Cullins for help in the design and construction of the equipment used.

\section{Appendix}

Tabulated below are the pressures obtained at various temperatures upon approaching the equilibrium pressure from above.

\begin{tabular}{c|r}
\hline \hline$T_{48}(\mathrm{~K})$ & $p($ torr $)$ \\
\hline 1023 & 0.087 \\
1043 & .124 \\
1070 & .225 \\
1078 & .238 \\
1083 & .300 \\
1084 & .315 \\
1113 & .492 \\
1136 & .657 \\
1151 & .803 \\
\hline
\end{tabular}

These measurements are represented by the equation

$$
\ln p=(17.85 \pm 0.67)-\frac{(20,720 \pm 730)}{T}
$$

for $p$ in torr; the uncertainties are the least squares estimates of the standard deviations of the parameters 
and the standard deviation of the fit is 0.07 in the logarithm of the pressure.

\section{References}

[1] Recently the use of $\mathrm{H}_{2}$ in an analogous manner was reported; cf. Lundin, C. E., "The Use of Thermodynamic Properties of "Metal-Gas Systems as Reduced-Pressure Standards" NASA Report CR-1271.

[2] Ariya, S. M., et al., J. Gen. Chem. USSR 25, 609 (1955).

[3] The symbols used in figure 1 are those adopted as standard by the AVS; see J. Vac. Sci. and Tech. 4, 139 (1967).

[4] Thomas, A. M., and Cross, J. L., J. Vac. Sci. and Tech. 4, 1 (1967).

[5] The high pressure ion gage used a Millitorr ${ }^{\mathrm{TM}}$ gage tube manufactured by Varian Associates, Vacuum Division, Palo Alto, California. This statement is for the purpose of information and does not constitute an endorsement or recommendation on the part of NBS.

[6] Yee, K. W., and Carpenter, R. J., Rev. Sci. Instr. 34, 1101 (1963).
[7] Natrella, M. G., Experimental Statistics, chapter 5, p. 10.

[8] cf. for example, Spedding, F. H., et al., Nucleonics 4, 4 (1949).

[9] Extremely slow rates of recombination have been noted in, for example, the $\mathrm{Si} / \mathrm{N}_{2}$ system; see Hincke, W. B., and Brantley, L. R., J. Am. Chem. Soc. 52, 48 (1930).

[10] Edmonds, T., and Hobson, J. P., J. Vac. Sci. and Tech. 2, 182 (1965).

[11] Bennett, M. J., and Tompkins, F. C., Trans. Faraday Soc. 53, 185 (1957).

[12] Lewis, G. N., and Randall, M., Thermodynamics as revised by Pitzer, K. S., and Brewer, L. (McGraw-Hill Book Co., New York, 1961).

[13] Latimer, W. M., J. Am. Chem. Soc. 73, 1480 (1951).

[14] Temperature: Its Measurement and Control in Science and Industry, Vol. 3, Ed. Herzfeld, C. M. (Reinhold, New York, 1962). 